\title{
Inovação na Administração Pública: O Programa de Modernização da Administração Financeira no Estado de Mato Grosso Quinze Anos Depois
}

\author{
Innovation in Public Administration: The Modernization Program of Financial \\ Management in Mato Grosso Fifteen Years Later
}

Renildes Oliveira Luciardo
Irani Aparecida Reinaldo
Isabel Cristina dos Santos
Laércio Baptista da Silva $^{3}$

Resumo: A abertura de mercado brasileiro ocorrida em 1990 compeliu os governos estaduais ao engajamento no Projeto de Modernização da Administração Pública, com a adoção do modelo de Administração Pública Gerencial, previsto no Programa Nacional de Apoio à Administração Financeira para os Estados Brasileiros. Este artigo visa identificar os aspectos do modelo que são considerados como inovação no setor público. A pesquisa, de caráter qualitativo e exploratório, focalizou as secretarias instrumentais do Governo do Estado de Mato Grosso. Os resultados indicam inovação no modelo de resolução de problemas, criação de novos serviços e melhoria nos processos. O comprometimento da alta administração com a implantação do novo modelo, considerado um fator crítico, não ocorreu de forma linear, gerando diferenças no grau de implantação do modelo entre as Secretarias do Estado.

Palavras-chave: Administração Pública; Inovação Organizacional; Modelo de Gestão.

Abstract: The Brazilian opening market in 1990 led to the State Governments to engage in the Public Administration Modernization Project, by adopting a managerial style of public administration, which was established in the National Program of Financial Management to the States. This article aims to identify which aspects of the model are considered as innovation in the public sector. This research has a qualitative approach is supported by an exploratory investigation, and it has been focused on the departments of the State of Mato Grosso. The results pointed out innovation in the model of problem solving, creation of new services and improvement processes. The senior management commitment with the implementation of the model, considered a critical factor, did not take place in a linear way, generating different degrees of model's implementation in the Secretaries of the State.

Keywords: Public Administration. Organizational Innovation. Management Model.

JEL: $\mathrm{H} 10$

\section{INTRODUÇÃO}

Os anos da década de 1990 foram marcados pela reforma do Estado, a recuperação da governança capacidade financeira e administrativa de implantar as decisões políticas tomadas pelo governo era um dos grandes problemas em relação à reforma do Estado.

A globalização da economia trouxe mudanças significativas tais como de

\footnotetext{
${ }^{1}$ Contadora. Doutoranda em Administração pela PPG/USCS. Professora da Universidade Federal de Mato Grosso. renildes.luciardo@uscs.edu.br

2 Administradora. Doutoranda em Administração pela PPG/USCS. iraniar@uscs.edu.br

3 Pós Doutora em Gestão da Inovação Tecnológica e da Economia da Inovação pelo Instituto Tecnológico de Aeronáutica (ITA). Professora do PPGA/USCS. isa.santos.sjc@uscs.edu.br

${ }^{4}$ Economista. Doutor em Controladoria e Contabilidade pela USP. Consultor da FECOMERCIO e

Professor da Universidade Municipal de São Caetano do Sul. lasilva@uscs.edu.br
} 
aspectos estruturais, tecnológicos, de recursos humanos e de investimentos e dessa forma a sociedade, sobretudo, dos países de industrialização recente, passou por uma revolução cultural e tecnológica, fato este que acentuou a necessidade de mudanças na administração pública brasileira e consequentemente do Estado de Mato Grosso.

A globalização associada à estabilização da economia exigia um modelo de Estado para integrar todo o ciclo financeiro, iniciando-se no planejamento através do PPA - Plano Plurianual, que deveria conter os meios (recursos) e instrumentos voltados para resultados, passando pela compatibilização da programação financeira e culminando com a avaliação da sua execução.

A manutenção do equilíbrio das contas públicas, consolidado pela Lei Complementar no 101 (Lei de Responsabilidade Fiscal) de 04 de maio de 2000, foi considerado o alicerce para a garantia da implementação do objetivo maior - a satisfação do cidadão. A busca do equilíbrio incluía a liberação de recursos para investimento público. Buscava-se, ainda, a redução dos encargos da dívida para o redirecionamento dos recursos liberados para investimentos na área social.

Assim, o Governo buscou um novo modelo de atuação, que foi implantado com o nome de Projeto de Modernização da Administração Financeira do Estado de Mato Grosso abrangendo as áreas de orçamento, controle orçamentário e financeiro, contabilidade, dívida pública, auditoria e controle interno.

O Programa de Reforma e Modernização do Estado de Mato Grosso foi implantado a partir de 1995, com a finalidade de concentrar a sua atuação em atribuições de segurança, defesa da cidadania, educação básica, saúde pública e indução ao desenvolvimento econômico. Visava ainda, manter na Administração Indireta apenas as entidades com capacidade financeira para se auto sustentarem, transferindo aos municípios os outros serviços que pudessem ser assumidos por eles, priorizar e promover articulação para atrair investimentos para o Estado (Barbosa e Gilioli, 1992).

O Projeto de Modernização da Administração Financeira do Estado de Mato Grosso implantado a partir de 1995, começa com a elaboração do Plano de Metas do Governo para o período 1995-2006 e, consolida-se quando Mato Grosso adere, em 1998, ao PNAFE (Programa Nacional de Apoio à Administração Financeira para os Estados Brasileiros) quando se inicia, de fato, a implantação do modelo de gestão Gerenciamento pelas Diretrizes com o uso do método PDCA, acrônimo para Planning, Do, Check, Act, termos que significam, respectivamente, planejar, executar, verificar (controlar) e agir corretivamente, de forma continuada.

Esse modelo de gestão Gerenciamento pelas Diretrizes que usa o método PDCA tem o cidadão como principal beneficiário, pela eficiência, qualidade na prestação dos serviços públicos, e desenvolvimento de uma cultura gerencial que atue na definição de objetivos e metas que avaliem os resultados alcançados em termos qualitativos e quantitativos.

Após quinze anos passados desde a adesão ao Projeto de Modernização este estudo busca responder a seguinte questão de pesquisa: 
Quais são as características observáveis na implantação do modelo de gestão que podem defini-lo como uma inovação para o setor público?

Desta forma, este estudo tem como objetivo geral: verificar as mudanças ocorridas com o Modelo de Gestão implantado a partir de 1998 nas Secretarias Instrumentais do Governo do Estado de Mato Grosso, bem como identificar se as características observadas deste se relacionam com os conceitos de inovação no setor público.

Como objetivos específicos, ou seja, aqueles que servem como caminho lógico a ser cumprido (etapas da pesquisa), tem-se os seguintes: a) verificar como está atualmente as Secretarias instrumentais em que foram implantados o Modelo de Gestão; b) levantar por meio de entrevistas informações que possam comparar as mudanças ocorridas nesses quinze anos de implantação do Modelo de Gestão em Mato Grosso; c) descrever as referências sobre as características de Inovação nas organizações; d) relacionar as características de inovação às do Modelo de Gestão de Mato Grosso implantadas nas Secretarias Instrumentais.

O produto deste estudo, além de contribuir para gerar informações avaliando as mudanças ocorridas nos últimos quinze anos da implantação do modelo de gestão, trará características que possam enquadrar processos executados na administração pública que sejam considerados como Inovação Organizacional.

Este artigo está dividido em quatro partes: contextualização do tema, problema e objetivo central de pesquisa, bases teóricas que orientaram a elaboração do trabalho em seguida a metodologia e resultados.

\section{FUNDAMENTAÇÃO TEÓRICA}

A partir da obra de Frederick Winslow Taylor (1856 - 1915), publicada em 1911, o século XX tornou-se o palco da formação das teorias de administração. E desde o seu nascedouro, as teorias organizacionais, sobretudo, da escola clássica buscavam meios e métodos de angariar maior eficiência, na operação e na gestão organizacional (Morgan, 1996).

Concomitantemente, Henri Fayol (1841-1925) fez a distinção entre funções administrativas e funções da empresa, nascendo daí vários desdobramentos das práticas de gestão. Para Fayol, administrar era o ato de prever, organizar, comandar, coordenar e controlar (Teixeira; Salomão e Teixeira 2010:174).

Seguidores de Fayol adicionaram suas contribuições nas descrições das funções administrativas, em destaque, Luther H. Gulick (1892-1983) que desenvolveu o modelo POSDCORB, cujas iniciais significam: Planning planejamento de ações e métodos para atingir os propósitos organizacionais; Organizing - estruturação formal das atividades; Staffing, treinamento dos participantes e criação de condições do trabalho; Directing, tomada de decisão, implementação e liderança; COordination, coordenação do interrelacionamento 
das várias etapas do trabalho; Reporting, comunicação das informações para conhecimento e ações; e, Budgeting; orçamentação, planejamento, contabilidade e controle na forma fiscal, das atividades organizacionais. $O$ modelo proposto por Gulick, aplicado pela primeira vez na administração pública, ampliou o conjunto das atribuições gerenciais, ensejando um perfil do novo gerente (Silva, 2005:150).

A partir dos anos 1920, Walter A. Shewhart (1891-1967) desenvolve, por meio de dados estatísticos, o controle de qualidade na produção. O modelo de Shewhart se expande além da área de produção e evolui na direção do modelo da Qualidade Total na década de 1940, tendo como pressuposto que a qualidade é um resultado sistêmico, do início ao fim do processo, considerando, inclusive, a qualidade dos recursos humanos, tecnológicos e materiais empregados.

O trabalho de Shewhart fez seguidores, dentre eles William Edwards Deming (1900-1993), um dos responsáveis pelo Sistema de Qualidade implantado no Japão, na década de 1950.

Em 1982, Deming lança o livro Quality, Productivity and Competitive Position, onde apresenta seus 14 princípios de qualidade, para tanto seria necessário utilizar um plano de ação, inicialmente, denominado "Ciclo de Shewhart", posteriormente "Ciclo de Deming" e, finalmente, Deming denominou o modelo como PDCA, (Maximiano, 2004). A figura 1 ilustra o modelo PDCA.

Desde então, o PDCA tem sido usado como uma técnica ou método gerencial utilizado no Gerenciamento pela Qualidade Total (GQT). De acordo com a teoria da Qualidade os ciclos de gerenciamento compõem-se de quatro fases simbolizadas pela sigla PDCA em inglês: Plan - Planejamento; Do Execução; Check - Avaliação; Action - Ação corretiva ou de padronização.

Figura 1 - Ciclo PDCA

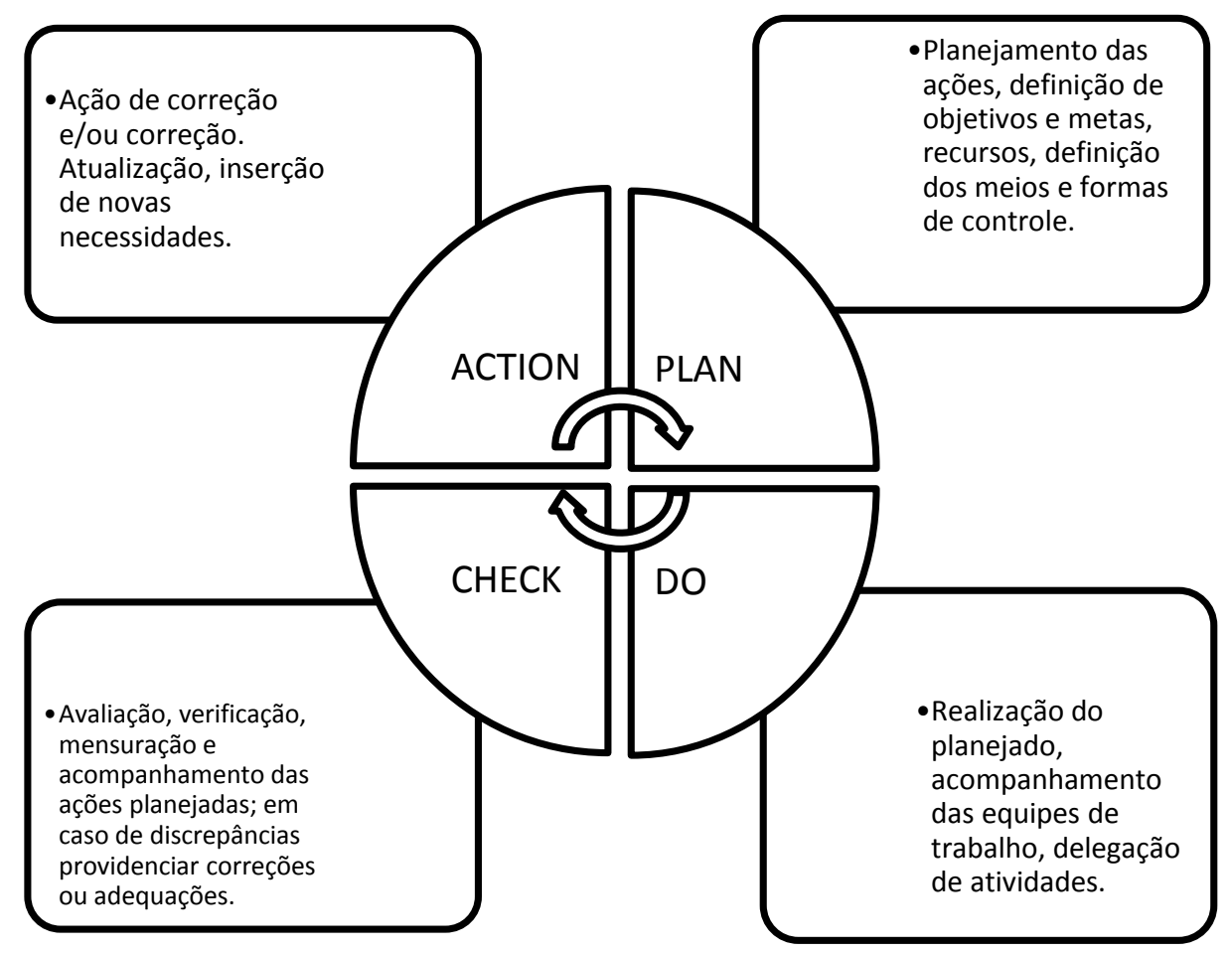


Fonte: Adaptado de Maximiano, 2004.

O PDCA, que foi pensado inicialmente para a área de produção (com Shewhart) e depois evoluiu para a administração (com a filosofia intrínseca ao modelo de Deming), e consequentemente na administração pública.

\subsection{O PDCA na Administração Pública}

O passo inicial para um processo administrativo é o planejamento (plan) que cria parâmetro e direcionamento para as demais funções administrativas, tais como gerenciamento, controle e avaliação de resultados (Teixeira e Santa, 1994). Planejar, portanto significa "traçar, elaborar ou fazer o plano; projetar, tencionar" (Ferreira, 2010:590). Durante a fase de planejamento as ações de tomada de decisões passam a ser fundamentais para o sucesso dos projetos.

A etapa do planejamento consiste em estabelecimento de metas sobre os resultados e estabelecimento do método para alcançar as metas propostas. Considera-se método, portanto, o "caminho para a meta" (Falconi, 1996a, p.36). Método pode ser um plano de ação, um projeto, um programa, um procedimento operacional padrão, uma política ou uma estratégia de gestão.

A execução (do) é o segundo passo do PDCA. Executar as tarefas exatamente como foi previsto na etapa de planejamento e coletar dados que serão utilizados na próxima etapa de verificação do processo. Segundo Sheffer (2000, p.37), nesta etapa, são essenciais a educação e o treinamento para o trabalho.

Avaliar (check) é o terceiro passo do PDCA. O verbete avaliar significa "determinar a valia ou o valor, calcular, estimar, reconhecer a intensidade, a força" (Ferreira, 2010:82). Portanto, para avaliar, é necessário um padrão de medida: altura, peso, densidade, moeda ou outros indicadores ou índices.

A partir dos dados coletados na execução é necessário comparar o resultado alcançado com a meta planejada, podendo assim obter avaliação de resultado e avaliação da execução.

A quarta etapa do PDCA refere-se à atuação corretiva (action). Esta etapa consiste em atuar no processo em função dos resultados obtidos. Existem duas formas de atuação possíveis: a) adotar como padrão o plano proposto, caso a meta tenha sido alcançada; e, b) agir sobre as causas de não consecução da meta, caso o plano não tenha sido efetivo.

Portanto, "avaliação de resultados ou da execução tem por objetivo uma decisão e ação correspondentes, aplicados para a melhoria ou manutenção daqueles resultados ou execução. É a retroalimentação do ciclo de gerenciamento" (Sheffer, 2000:39).

A retroalimentação do ciclo de gerenciamento é feita através das formas de atuação distintas: a) Agir corretivamente: Em caso de resultados insatisfatórios, elabora-se um plano de ação corretiva. Em caso de desvios na 
execução dos planos, deve-se corrigir o planejamento ou a execução do plano, dependendo de onde se localizar o problema; b) Padronizar: Em caso de resultados satisfatórios, o plano se torna um procedimento operacional padrão que representa um caminho garantido para aquele resultado.

Verifica-se que a implantação do método PDCA vai ao encontro do movimento dos anos 1990 pela busca da Gestão da Qualidade Total (GQT) sendo aplicada também à administração pública reconhecendo que uma perspectiva interessante de que não há espaço em viabilizar processos sem que estes estejam vinculados a algum resultado e pela "necessidade de se desenvolver um referencial sobre a GQT em ambientes públicos que possibilitasse caracterizá-la como uma técnica gerencial positivamente utilizável." (Gomes, 1997:49).

A implantação de novos modelos de gestão pressupõe a eliminação de barreiras, entre as quais vale citar: a falta de políticas públicas claramente definidas; a descontinuidade administrativa, que interrompe ações em andamento e dificulta o processo decisório; o despreparo dos quadros funcionais, notadamente os de nível gerencial; a tendência à concentração do poder, que resulta em centralizações excessivas; a visão reducionista da realidade, que leva a centrar no governo federal as decisões sobre uma gama infinda de problemas da competência dos estados e municípios. (Carvalho e Tonet, 1994:150)

Essa busca pela qualidade total na administração pública consequentemente leva a aprimorar os métodos de gestão surgindo inovação nos procedimentos fato este que será comentado no próximo subitem.

\subsection{A Inovação na Esfera da Administração Pública}

Até o final do século $X X$, poucos estudiosos se preocupavam com pesquisas sobre inovação no setor público, um estudo bibliométrico realizado por Matthews et al (2009) aponta que no período de 1970 até o ano de 2008, um crescimento geométrico somente a partir de 2005 - de 22 para 42 artigos sobre o assunto.

O mérito de iniciar os processos de inovação no setor público cabe à Austrália, que possui, inclusive, um guia elaborado pelo National Audit Office NAO - que serviu de apoio para a OCDE, introduzir um setor em seu site para tratar do assunto.

As discussões sobre inovação têm tomado uma dimensão maior no século $\mathrm{XXI}$, bem como a aplicação de significados em todos os setores (Queiroz e Ckagnazaroff, 2010). A própria palavra, original do latim innovare, traduz-se em inserção de novidades, pode-se então entender que inovação cabe a qualquer tipo de novidade em qualquer área.

Entretanto, este conceito foi mais utilizado nos setores produtivos, dando a ideia não só de novidade, mas de invenção e introdução de novos produtos 
seguidos de aceitação pelos consumidores e retornando como aumento de capital, favorecendo, assim o desenvolvimento econômico.

Adam Smith (1723-1790) já explorava as causas de acúmulo de capital relacionado à inserção de tecnologia da manufatura. Mas é Schumpeter (1982:48-49) que traz uma definição mais abrangente do conceito de inovação, definindo-a em cinco estágios, quais sejam: a) Introdução de um novo bem, b) Introdução de um novo método de produção, c) Abertura de um novo mercado, d) Conquista de uma nova fonte de oferta de matérias-primas ou de bens semimanufaturado, e) Estabelecimento de uma nova organização.

Observa-se que a conceituação de Schumpeter está claramente voltada para a indústria, entretanto, analisar as circunstâncias de inovação exige uma amplitude do conceito, considerando os aspectos organizacionais e sociais. Dosi (1988) define que a inovação está relacionada tanto à descoberta como à experimentação, dessa forma envolve correr riscos e nem sempre envolve aumento do capital ou traduz-se em desenvolvimento econômico, mas pode proporcionar melhorias, por exemplo, na prestação de um serviço ou na introdução de transparência dos resultados alcançados.

Complementando esse entendimento conceitual Tidd, Bessant e Pavitt (2008) dividem a inovação em dois grandes grupos: inovação tecnológica (produtos e processos) e inovação organizacional (marketing, modelos de negócios, estrutura). Os autores enfatizam que cada vez mais a inovação está se tornando uma tarefa corporativa ampla, pressionando para a mudança organizacional amplamente disseminada em direção a modelos mais orgânicos (Tidd, Bessant e Pavitt, 2008:492).

Num esforço de ampliar o entendimento no Manual de Oslo, que é a referência mundial sobre os procedimentos de inovação, observa-se a seguinte definição:

Uma inovação é a implementação de um produto (bem ou serviço) novo ou significativamente melhorado, ou um processo, ou um novo método de marketing, ou um novo método organizacional nas práticas de negócios, na organização do local de trabalho ou nas relações externas. (Manual de Oslo, 2005:55).

Consequentemente, a inovação organizacional e de serviços passa a ser, em grande medida, o papel do Estado, Currie et al 2008 apud Matthews et al (2009:21) definem inovação no setor público como uma questão de criatividade, inusitado ou novidade na solução de problemas ou necessidade, incluindo novos serviços, novo formato organizacional e melhoria de novos processos.

Mulgan and Albury (2003) complementam dizendo que o sucesso da inovação é a criação e implementação de novos processos, produtos, serviços e métodos de transmitir cada resultado com significante melhoria e consequente eficiência, efetividade ou qualidade.

Matthews et al (2009:21) classificam a inovação em três grupos: 

existentes.

- incremental: pequenas mudanças nos serviços ou processos

- $\quad$ radical: novos serviços, produtos ou métodos (performance), mas a dinâmica do setor permanece inalterada.

- $\quad$ sistêmico ou transformacional: grandes inovações, muitas vezes impulsionadas pelo surgimento de novas tecnologias, que transformam setores, dando origem a novas estruturas da força de trabalho, novos tipos de organização, novas relações entre as organizações e mudança radical no desempenho geral.

A implementação bem sucedida da inovação no setor público segundo Matthews et al (2009:29), observa clareza dos objetivos, fortes incentivos, boas ideias, ausência de barreiras e meios aprendizagem e replicação dos resultados.

Os autores enfatizam a importância de se utilizar o método PDCA, para alinhamento da inovação no setor público, propondo, entretanto, a mudança da letra "A" para ajuste e adaptação das etapas, sendo, assim apresentado: Plan, Do, Check e Adjuste. A Figura 2 oferece a síntese da proposta de Matthews et al (2009).

Figura 2 - Etapas para implantação bem sucedida da inovação

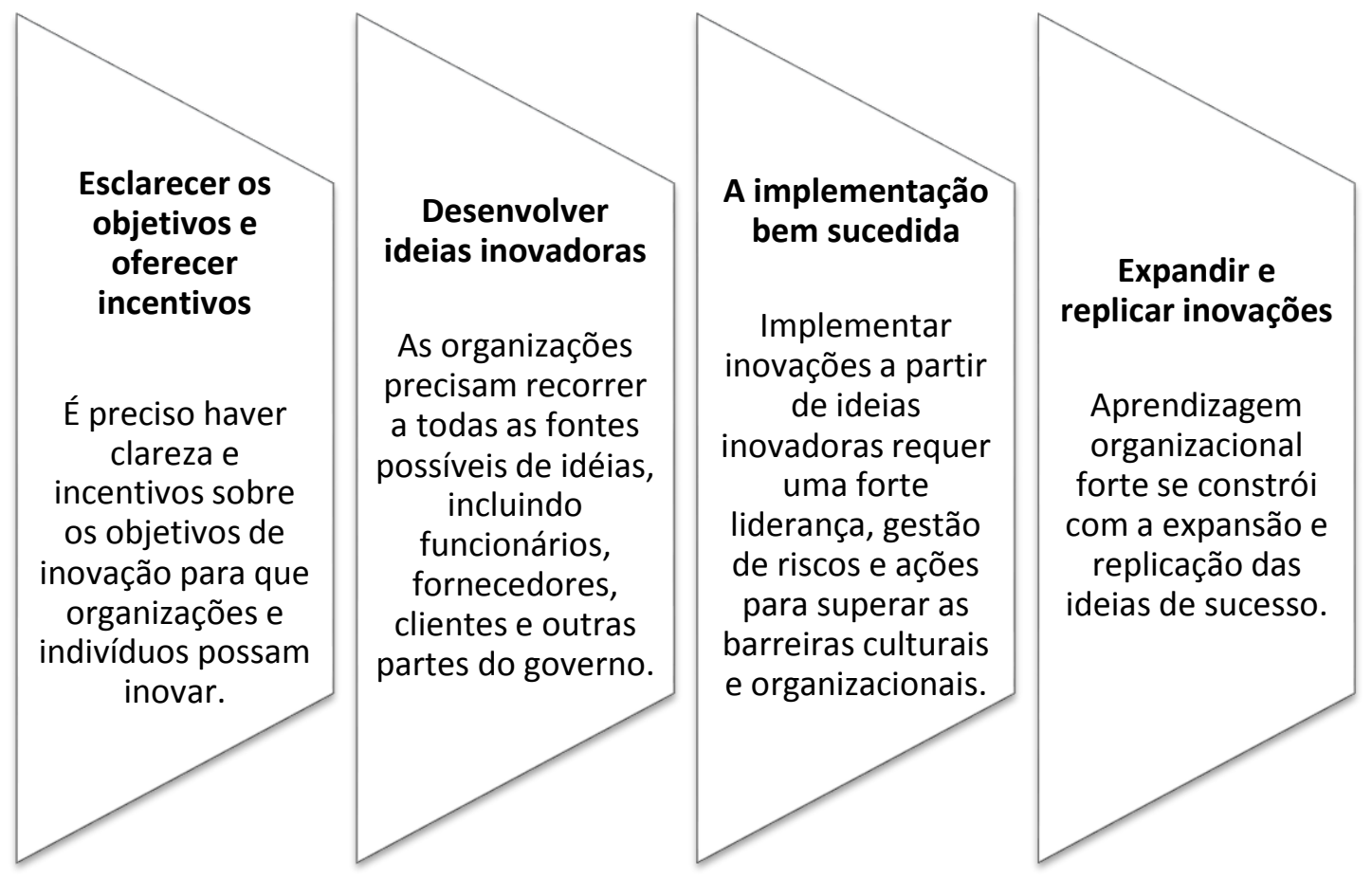

Fonte: Matthews et al (2009, p. 29)

Para descrição dos casos de inovação o Manual de Oslo propõe os seguintes dados de análise: Descrição da inovação principal, Classificação por tipo de inovação e grau de novidade da inovação. 
Os fatores acima descritos, mesmo preponderantes do setor industrial, também servirão de base para justificar a Gestão pelas Diretrizes implantada nas Secretarias Instrumentais e Secretaria de Fazenda do Estado de Mato Grosso como características de inovação no serviço público.

\section{METODOLOGIA}

Esta pesquisa, pelos procedimentos utilizados, constitui-se em um estudo de caso, que compreendeu o universo dos órgãos que compõem a Administração Financeira do Governo do Estado de Mato Grosso (a área instrumental). Estudo de Caso pode ser definido como "uma categoria de pesquisa cujo objeto é uma unidade que se analisa profundamente" (Triviños 1987:133).

Quanto aos objetivos da pesquisa, esta pode ser classificada como pesquisa exploratória (Gil, 1996 e 1999).

O estudo deste trabalho inicia-se tomando como base os resultados apresentados por Luciardo (2000) que efetuou uma análise ao Modelo de Gestão em implantação nas Secretarias Instrumentais do Governo do Estado de Mato Grosso, visando a apresentar um estudo sobre Avaliação de Desempenho vinculada à Proposta Orçamentária. Este estudo foi feito mediante um Estudo de Caso que teve início com a realização de uma pesquisa documental, objetivando levantar como se encontrava o processo de Planejamento/Orçamento no Estado de Mato Grosso.

$\mathrm{Na}$ época, Luciardo (2000) com base em documentos próprios da instituição, e ali indicados como o Projeto de Modernização da Administração Financeira do Estado de Mato Grosso, Plano Plurianual-PPA - período 20002003, Projeto de Lei de Orçamento Fiscal, Seguridade Social e Investimentos Exercício de 2000, colheu informações que levaram a compreender aspectos atuais e a evolução da avaliação de desempenho vinculada à proposta orçamentária. Na segunda parte da sua pesquisa, utilizou como instrumento a "entrevista semiestruturada - esta, ao mesmo tempo que valoriza a presença do investigador, oferece todas as perspectivas possíveis para que o informante alcance a liberdade e a espontaneidade necessárias, enriquecendo a investigação" (Triviños 1987:146).

Dando continuidade e procurando comparar os resultados da pesquisa de Luciardo (2000) com as ocorrências encontradas nestes quinze anos da implantação do modelo de gestão em Mato Grosso, este estudo utiliza-se da técnica de entrevista Delphi realizada com um especialista de cada setor replicando algumas das questões do roteiro utilizado na pesquisa anterior.

Neste sentido, utilizou-se o mesmo roteiro prévio de perguntas com algumas adaptações buscando esclarecer os objetivos específicos deste estudo, possibilitando construir a base de dados para análise. 
As entrevistas se realizaram no período de 25 de abril a 30 de maio de 2013 sendo o contato feito pessoalmente e o roteiro com as perguntas enviadas por email aos entrevistados selecionados.

Foram realizadas quatro entrevistas sendo que dos entrevistados incluem-se atores dirigente e técnicos pertencentes à equipe responsável pela elaboração do projeto de modernização da administração pública, todos pertencentes aos órgãos da Administração Financeira do Estado (Secretaria de Planejamento, de Fazenda e Auditoria Geral do Estado), órgãos estes considerados instrumentais do projeto de modernização da administração pública.

Este estudo procura estruturar o conteúdo das entrevistas, selecionando o material a ser trabalhado na descrição, utilizando-se dos procedimentos apresentados por Bogdan e Biklen (1994).

\section{RESULTADOS E ANÁLISE}

\subsection{O Caso de Estudo}

O processo de inovação na Gestão Pública no Estado do Mato Grosso iniciou-se em 1998 com a implantação do Modelo de Gestão Gerenciamento Pelas Diretrizes (GPD), bem como com a utilização do método PDCA nas Secretarias de Administração, Fazenda, Planejamento e Auditoria Geral do Estado, devido sua facilidade e clareza, tais como definição de metas, controle da execução, análise das informações e tomadas de decisão (Figura 4).

Uma das principais mudanças foi implantar um sistema de planejamento voltado para resultado e para isso mudou-se o foco dos objetivos estratégicos para as atividades fins.

O sistema de planejamento voltado para resultado foi sistematizado a partir de uma referência acerca da missão, objetivos e clientela da organização, estabelecimento de Metas com objetivo, valor e prazo; passando a traduzir responsabilidades específicas ao (PPA) que foi preparado com Padrão Gerencial (Regulamento); Negociação das Metas; Capacidade de concretização (através do Plano de Ação); Estratégia participativa na montagem do sistema (garantia do comprometimento com o sistema de avaliação estabelecido); Simplicidade - facilidade para ser compreendido e acessado; Definição das dimensões de atuação e este modelo deveria ter um Sistema de Informações que desse suporte ao Modelo de Gestão voltado ao apoio à elaboração e para avaliação dos Planos.

Para implantar um modelo orçamentário voltado para resultado, o Governo de Mato Grosso teve como ponto de partida o Plano de Metas elaborado em 1994 para o período de 12 anos (1995/2006) conforme figura 4: 


\section{Figura 3 - objetivos de longo prazo - planejamento estratégico de Mato Grosso.}

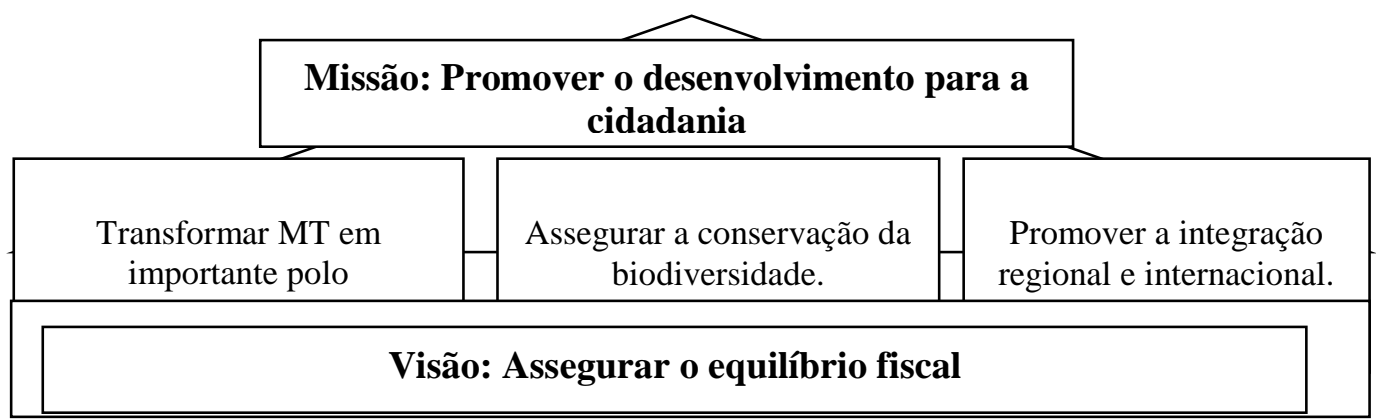

Fonte: PPA/MT 2000-2003, 1999:32

Assim com base no Planejamento Estratégico, foram estabelecidas seis metas de Longo prazo para o PPA (2000-2003): Melhorar o Índice de Desenvolvimento Humano-IDH em 10\% até Dezembro de 2003; Reduzir os Custos de transporte no Estado essencial para dar competitividade aos nossos produtos, em 2\%; Aumentar o valor da produção industrializada do Estado em 30\%; Assegurar a Proteção e utilização racional de 100\% dos recursos naturais do Estado; Triplicar o valor das exportações de bens e serviços e Assegurar o Equilíbrio Fiscal

Quanto ao Gerenciamento pelas Diretrizes (GPD) é um Sistema de Gestão, que conduz ao estabelecimento e a execução do Plano Anual, usa o método PDCA, e segundo Falconi (1996b) "O Gerenciamento pelas Diretrizes é um mecanismo que concentra a força intelectual de todos os funcionários, focalizando-a para as METAS de sobrevivência da organização".

No planejamento da GPD, a meta foi constituída de três partes: a) um objetivo gerencial; b) um valor; c) um prazo. O valor estabelecido deve ser atingível e rigoroso; a meta deve ser colocada por escrito em lugar onde todos possam ver, com gráfico do item de controle, situação atual levantada, o valor e seu posicionamento; quanto mais visível melhor. No nível mais elevado da estrutura organizacional, as Metas e os indicadores são fortemente relacionados aos objetivos e estratégias da organização;

À medida que são desdobradas na estrutura, estas passam a ser influenciadas pelas metas e indicadores superiores. As Diretrizes são desdobráveis e os Diretores do nível hierárquico inferior estabelecem suas metas a partir das medidas da alta Administração. Quando uma medida é não desdobrável, faz-se um plano de ação $(5 \mathrm{~W} 1 \mathrm{H})$ : what: o que; who: quem; when: quando; where: onde; why: por que; how: como.

Já a verificação dos resultados percorre o caminho inverso do desdobramento. Para verificar o atingimento das metas é necessário verificar continuamente os itens de controle, por exemplo, análise dos pontos problemáticos por quem estabeleceu e implementou o Plano de Ação por meio de um Relatório de Reflexão entre as metas e os resultados alcançados, determinando as causas do desvio e estabelecendo medidas corretivas (contramedidas). 
A figura 4 apresenta uma síntese de como o método PDCA foi adotado no processo de inovação e ao mesmo tempo as responsabilidades de cada órgão, subdivididas em cada quadrante do PDCA.

\section{Figura 4 - Responsabilidades de cada setor no PDCA}

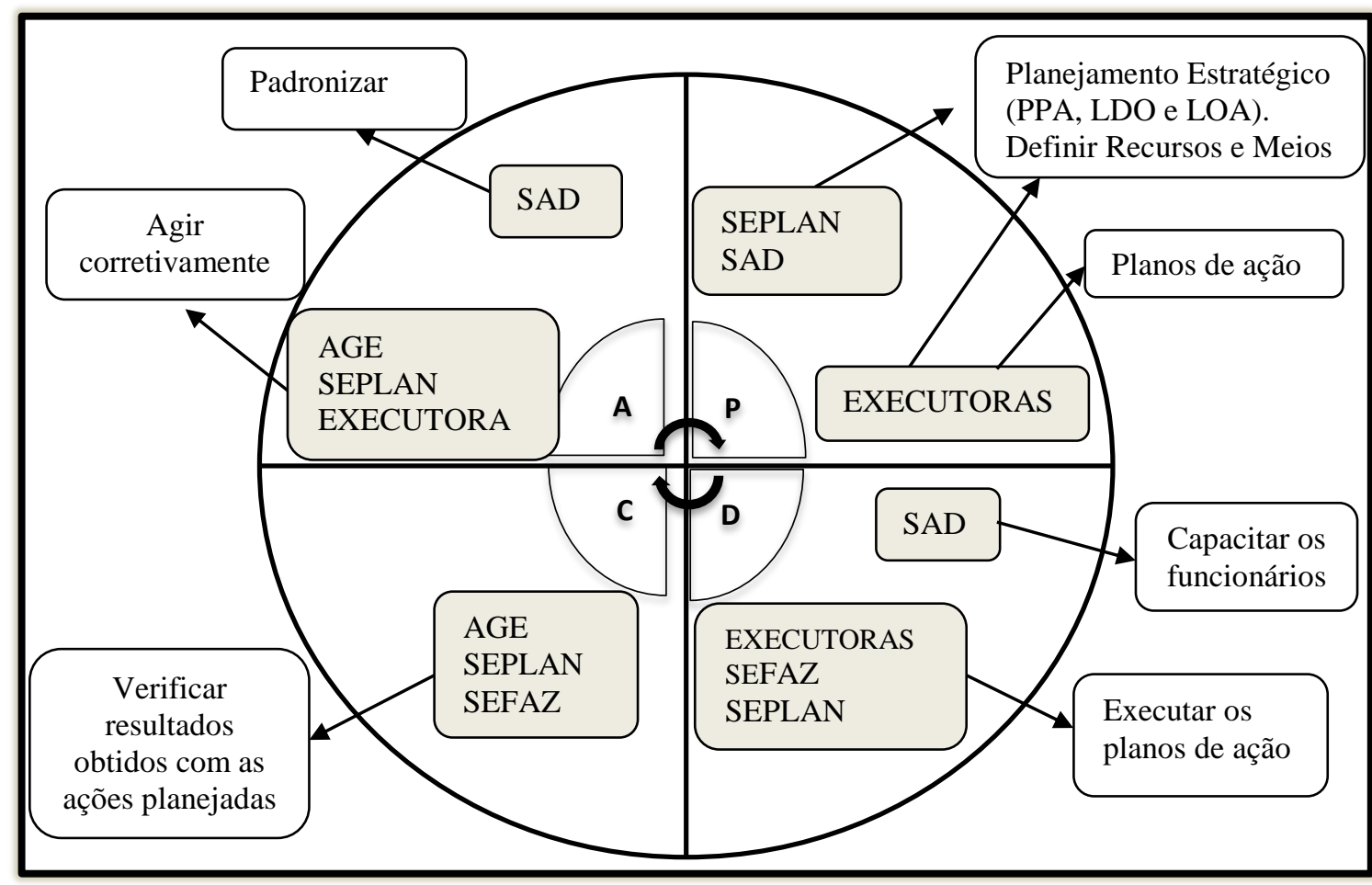

Fonte: PPA Governo do Estado/MT - 2000-2003, 1999.

Legenda: SEPLAN: Secretaria de Estado de Planejamento; SAD: Secretaria de Estado de Administração; SEFAZ: Secretaria de Estado de Fazenda; AGE: Auditoria Geral do Estado; Executoras: Secretarias de áreas fins

Este modelo possibilitava a administração pública de Mato Grosso avaliar as suas ações a partir da proposta orçamentária.

O ponto alto do Gerenciamento pelas Diretrizes é o estabelecimento do "Regulamento" que se torna praticamente um contrato de gestão, um pacto, celebrado com o envolvimento de todos os níveis hierárquicos da organização, culminando com o "Relatório de Não-Conformidade", "Relatório de Reflexão" e o "Diagnóstico" onde a Alta Administração acompanhará durante o exercício e verificará em Dezembro, o alcance das metas decorrentes de sua Diretriz e se o método está sendo corretamente aplicado.

As evidências demonstradas neste trabalho levam a concluir que o êxito de uma gestão que privilegie a Avaliação de Desempenho, está não só na correta escolha da metodologia, mas do comprometimento da Alta Administração, fazendo com que se cumpra a execução de todos os procedimentos nos prazos estabelecidos no Regulamento do Gerenciamento pelas Diretrizes. 


\subsection{Resultados Obtidos}

Para efetuar a análise, esta parte traz a descrição das questões, em seguida as respostas consideradas significativas visando atender aos objetivos específicos desta pesquisa.

\section{Quadro 1 - Resultado das Entrevistas realizadas.}

\section{1) Você tem conhecimento do objetivo do modelo de gestão?}

Ator 01: O modelo de gestão era alinhado com o movimento da Administração Pública Gerencial ou Pós-burocrática, que tem como grande desafio deslocar a ênfase dos meios para os fins na Administração. Ele também tinha forte influência da Gestão pela Qualidade Total, em virtude da consultoria prestada na época pela Fundação de Desenvolvimento Gerencial (FDG), liderada pelo consultor Vicente Falconi

Ator 02: Desenvolver competências de planejamento.

Ator 03: $\mathrm{NH}$

Ator 04: baseado no modelo de gestão hoje temos um mapa estratégico com base nele se baseiam todas as ações. O modelo foi fundamental para as mudanças que estão se processando hoje na gestão.

2) O que a comunidade tem a ganhar com a implantação desse modelo de gestão?

Ator 01: A comunidade tem a ganhar muito, com a introdução de ferramentas de gestão que possam focar a geração de resultados na Administração Pública. Um dos pressupostos fundamentais do modelo é a ênfase no cidadão-usuário de serviços públicos. Portanto, a desburocratização tem como objetivo facilitar a vida do cidadão no seu convívio com a Administração Pública. Outro aspecto importante é a transparência, trabalhada pela Qualidade Total como Gestão à Vista

Ator 02: O cumprimento da LRF, com a transparência da aplicação dos recursos públicos.

Ator 03: $\mathrm{NH}$

Ator 04: $\mathrm{NH}$

3) Do modelo implantado o que ficou? Poderia descrever?

Ator 01: A maior parte do legado do modelo ficou nas secretarias da área sistêmica (SAD, Seplan, Sefaz e AGE), além do Cepromat. Todos eles tiveram ações financiadas pelo PNAFE, que foi um programa com recursos do Banco Interamericano de Desenvolvimento (BID) para modernização da gestão. Cito algumas inovações que permanecem até hoje: 1 - A estrutura de atendimento da Sefaz, com destaque para as agências fazendárias e toda a implantação de tecnologia da informação na área tributária; 2 - A carreira de Gestores Governamentais; 3 - Mudanças nos instrumentos de planejamento governamental, como a introdução do Plano de Trabalho Anual (PTA) como elo entre plano e orçamento. 4 - Infovia, que é uma estrutura lógica para processamento de dados comandado pelo Cepromat.

Ator 02: Pelo que observo hoje, ficou a utilização de metas em algumas unidades e do procedimento operacional para atingimento de metas.

Ator 03: $\mathrm{NH}$ 
Ator 04: Hoje a Sefaz está com a maioria dos serviços informatizados, o contador tem senha e pode entrar na Secretaria de fazenda e obter vários serviços e isso facilita pois ele pode fazer os serviços referentes à SEFAZ em sua empresa mediante cartão digital. Isso facilitou e agilizou. A questão do Gerenciamento pelas Diretrizes continua, o PTA continua, as Capacitações de acordo com o levantamento das necessidades de cada unidade continuam. Estão também desenvolvendo a avaliação por desempenho e vai ser implementado ano que vem. Este ano parou por contingenciamento no orçamento. Já está tudo pronto, tudo mapeado, então o servidor vai ser avaliado conforme o seu desempenho. Mas mantém-se hoje todo esse processo que iniciou com a modernização, mantêm-se aqui na Sefaz as reuniões quinzenais com as coordenadorias, as Gerencias também fazem suas reuniões em datas diferentes. Nas reuniões sistemáticas apresentavamse os indicadores para avaliar as ações, hoje tem o SIGPEX que é um sistema criado que possibilita o acompanhamento da ação, de acordo com a Matriz tem-se o Processo e cada processo vários produtos, deixou então de analisar por caixinhas, cada processo cada caixinha de produtos. Hoje já se analisa direto as ações, pois elas são colocadas no sistema que avalia ação planejada/ação executada. Agora avalia pelo SIGPEX. Mas antes a outra consultoria orientou para elaborar a Matriz, relacionar seus fornecedores, relacionais seus insumos, relacionar os processos de cada processo saia o produto, o responsável pela ação escolhia um produto para se trabalhar, iria analisar a necessidade de seus clientes, analisaria seus indicadores de processo, os resultados para estar avaliando, mas depois veio uma consultoria que esse processo gasta-se muito tempo escrevendo do que executando e eliminou-se tudo, trabalha-se só o produto. E agora já mudou é o tal do SIGPEX.

4) Nesse período todo desde a implantação: Alguma meta ou programa completou o ciclo desde o planejamento até a avaliação e aplicação de ação corretiva, ou padronização, ou identificou desvios? Dê exemplos

Ator 01: Vou reunir os documentos da época com estas informações e te passar.

Ator 02: Que eu tenha conhecimento e evidências não.

Ator 03: $\mathrm{NH}$

Ator 04: Não posso afirmar. Não tenho evidências.

5) O que dificulta ou que problemas enfrenta a implantação do modelo?

Ator 01: As dificuldades são aquelas encontradas por toda reforma na gestão pública, como a resistência dos servidores por inovações e a ênfase nos procedimentos que é a própria da Administração Pública burocrática.

Ator 02: Não ser o modelo que os líderes apoiavam até sua total implementação.

Ator 03: NH

Ator 04: A base do Modelo era a Gestão pela Qualidade Total, que enfatiza os clientes de qualquer organização e é difícil de praticar no setor público mas não impossível. Pois o conhecimento está sendo disseminado na SEFAZ haja visto os cursos de qualificações, as consultorias, etc.

6) O que o modelo mais trouxe de vantagens após sua implantação?

Ator 01: A principal vantagem foi a introdução de novas metodologias de gestão no Governo, que estão em uso até hoje, e a formação de quadros 
profissionais para a Administração Pública.

Ator 02: Não sei dizer, pois me parece que não foi totalmente implantado.

Ator 03: $\mathrm{NH}$

Ator 04: $\mathrm{NH}$

7) Que caminhos se apresentam no atual estágio de sua implantação?

Ator 01: No momento atual o modelo enfrenta alguns problemas. Primeiro, a necessidade de uma melhor formalização, já que houve uma série de mudanças ao longo do Governo Blairo Maggi (2003-2010), como a criação dos Núcleos Sistêmicos. Há várias ferramentas e práticas gerenciais hoje desarticuladas entre si e sem foco. Segundo, o imperativo de enfatizar mais os programas de qualidade, criando um prêmio estadual de qualidade como outros Estados têm. O fortalecimento do Núcleo Estadual do Programa Gespública também é chave neste contexto.

Ator 02: Não sei dizer, pois hoje não sei qual o modelo de gestão que é adotado - se por resultados, por estratégias, por competências - não está claro pra mim.

Ator 03: NH

Ator 04: A forma de fazer esses gerenciamentos, elas mudaram várias vezes e talvez por isso dificultou a internalização dos gestores. Tem gestores que não resultados melhor nas agências deles, porque faltou uma padronização.

8) Que avaliação você faria com relação a implantação do modelo?

Ator 01: A implantação foi bem sucedida em parte, em função da mudança de cultura gerencial em alguns setores e do legado que já apontei em outras respostas.

Ator 02: De 1 a 10? Ficou no 5.

Ator 03: Foi bom, pois hoje essas secretarias estão bem equipadas, alguns procedimentos e ferramentas são utilizadas, como trabalhar com metas, gestão pela qualidade e isso foi muito bom para a Sefaz principalmente.

Ator 04: Os padrões do gerenciamento pelas diretrizes, trabalhar com matriz, com orientação para resultado trouxe resultado positivo. Agente trabalha sabendo o que deve ser feito e coloca no SIGPEX para avaliar o resultado.

9) O que poderia ser melhorado para obter melhores resultados?

Ator 01: Principalmente maior prioridade do Governo para a área de gestão. Hoje esta agenda está um pouco órfã, sem um órgão que seja seu titular e a encabeça. Portanto, falta uma gestão mais clara para a gestão de uma forma geral e em particular, diretrizes para as ferramentas da qualidade total.

Ator 02: Desenvolver as competências de planejamento e lideranças para as pessoas responsáveis pelos resultados da organização.

Ator 03: $\mathrm{NH}$

Ator 04: Não sei dizer

10)O que é mais importante fazer com a utilização do modelo para ser possível avaliar os programas e a gestão?

Ator 01: Várias providências, como melhoria na formulação dos objetivos, indicadores e metas físicas; melhor acompanhamento durante a execução; mais clareza metodológica na fase da avaliação, etc.

Ator 02: Colocar resultados que são necessários pelo cidadão e com a avaliação e divulgação periódica do mesmo.

Ator 03: $\mathrm{NH}$ 


\begin{tabular}{|c|}
\hline $\begin{array}{l}\text { Ator 04: } \mathrm{NH} \\
\text { 11)Quanto à sua participacão no trabalho sente-se intearado no processo? }\end{array}$ \\
\hline Ator 01: Sim. Tive a oportunidade de participar em algumas etapas. \\
\hline Ator 02: Só no nível operacional. \\
\hline Ator 03: NH \\
\hline Ator 04: No Nível Operacional \\
\hline 12)Facilitou o andamento (desempenho) das suas func \\
\hline Ator 01: Sim. Naquilo que me cabia, tentei contribuir. \\
\hline $\begin{array}{l}\text { Ator 02: Conhecer e praticar o modelo, sim facilitou o desempenho das } \\
\text { minhas funções. }\end{array}$ \\
\hline Ator 03: NH \\
\hline $\begin{array}{l}\text { Ator 04: A melhoria nos processos facilita e muito o desempenho das nossas } \\
\text { funções. }\end{array}$ \\
\hline $\begin{array}{l}\text { 13)Como você vê a função da contabilidade no processo de implantação do } \\
\text { modelo? }\end{array}$ \\
\hline $\begin{array}{l}\text { Ator 01: A contabilidade é fundamental como registro das transações } \\
\text { financeiras e patrimoniais executadas pelo Poder Executivo. Ela também se } \\
\text { tornar mais gerencial, com a adoção de metodologias inovadoras como ABC, } \\
\text { rateio de despesas por centro de custo, dentre outras. }\end{array}$ \\
\hline $\begin{array}{l}\text { Ator 02: A função seria de controladori } \\
\text { também os resultados alcançados para o }\end{array}$ \\
\hline Ator 03: $\mathrm{NH}$ \\
\hline Ator 04: Não tenho como responder, não possu \\
\hline $\begin{array}{l}\text { 14)As informações da contabilidade estão sempre disponíveis nos momentos } \\
\text { certos, da forma integrada? Explique. }\end{array}$ \\
\hline $\begin{array}{l}\text { Ator 01: As formas de acesso às informações são definidas pela legislação } \\
\text { específica, como a Lei Complementar federal } 131 / 2009 \text { e a Lei federal de } \\
\text { Acesso à Informação (12.527/2011). O cumprimento destas normas é que } \\
\text { deve ser avaliado. }\end{array}$ \\
\hline Ator 0 \\
\hline Ator 0 \\
\hline Ator 04: Não sei dizer. Não possuo conhecimento a respeito. \\
\hline $\begin{array}{l}\text { 15)E a informática, dispõe de equipamentos e pessoal técnico capaz de dar } \\
\text { suporte a implantação do modelo? }\end{array}$ \\
\hline $\begin{array}{l}\text { Ator 01: De forma geral, a estrutura é boa. Ainda existem deficiências de } \\
\text { hardwre, software e pessoal em alguns pontos e que precisam ser sanados. }\end{array}$ \\
\hline 2: Pelo \\
\hline Ator 03: NH \\
\hline $\begin{array}{l}\text { Ator 04: Sim, temos hoje o SIGPEX e outros programas como esse que cria o } \\
\text { canal de comunicação do sistema tributário com os contadores. Mas para o } \\
\text { modelo de gestão em específico falta desenvolver sistemas. }\end{array}$ \\
\hline $\begin{array}{l}\text { 16)Como se dá hoje a Avaliação de Desempenho na Administração Pública } \\
\text { de Mato Grosso? O que mudou com relação a avaliação anterior? }\end{array}$ \\
\hline $\begin{array}{l}\text { Ator 01: A avaliação de desempenho de órgãos e unidades ainda é muito } \\
\text { empírica, sem uma metodologia que a organize, como a adoção de acordos } \\
\text { de resultados como em outros Estados. As metas são especificadas nos } \\
\text { instrumentos de planejamento, mas não há uma sistemática plena de } \\
\text { monitoramento que os valorize. }\end{array}$ \\
\hline
\end{tabular}


Ator 02: Não sei dizer.

Ator 03: $\mathrm{NH}$

Ator 04: Não sei dizer. Não tenho subsídios para responder esta pergunta.

17)Que caminhos a administração pública do Estado de Mato Grosso apresenta para Avaliação de Desempenho da gestão de despesas públicas vinculada à proposta orçamentária?

Ator 01: Hoje a prática neste sentido ainda é muito incipiente. Os critérios para alocação de despesas ainda são muito mais políticos do que técnicos.

Ator 02: Não sei dizer.

Ator 03: $\mathrm{NH}$

Ator 04: Não tenho subsídios para responder esta pergunta.

Fonte: Dados da pesquisa, elaborada pelos autores.

\subsection{Análise e Discussão dos Resultados}

Para fazer a análise este estudo buscou os mesmos parâmetros condicionantes para inovação, sendo observado que as condições técnicas, apresentadas no Quadro 2, foram importantes para a implantação do Modelo Gestão pelas Diretrizes com o Método PDCA.

\begin{tabular}{|c|c|}
\hline Condições Técnicas & Implantado \\
\hline $\begin{array}{l}\text { Sistema } \\
\text { Conhecimento }\end{array}$ & Inserção da técnica de gestão PDCA \\
\hline $\begin{array}{l}\text { Capacidade } \\
\text { Tecnológica }\end{array}$ & $\begin{array}{llll}\text { Tecnologias de } & \text { Informação } & \text { e } \\
\text { Comunicação. } & & & \end{array}$ \\
\hline Capacidade Humana & $\begin{array}{llll}\text { Treinamento e } & \text { Capacitação dos } \\
\text { Servidores } & & & \\
\end{array}$ \\
\hline Rede de Usuários & $\begin{array}{l}\text { Acessibilidade direta à SEFAZ aos } \\
\text { contadores por meio de senha. Serviços } \\
\text { diretos ao cidadão. }\end{array}$ \\
\hline
\end{tabular}

Fonte: Elaborada pelos autores.

Outra fonte de análise parte dos itens descritos por Luciardo (2000) relacionando-os aos resultados da entrevista desta pesquisa, referentes aos detalhes de implantação do Sistema de Gerenciamento pelas Diretrizes, nos últimos quinze anos conforme apresentado no Quadro 3:

Quadro 3 - Análise da implantação do Modelo de Gestão (1998 a 2013)

Referente item: Gerenciamento pelas Diretrizes

Pode-se perceber pelas respostas dos atores que alguns procedimentos constantes do Manual do Gerenciamento pelas Diretrizes ainda são seguidos: estabelecimento 
de metas, ter como foco o produto e as reuniões quinzenais para discussão dos resultados das ações entre as Gerências.

Referente item: Uso do método PDCA

Os entrevistados ao serem questionados sobre se alguma meta ou programa se completou o ciclo desde o planejamento até a avaliação e aplicação de ação corretiva, ou padronização, ou identificou desvios, pedindo que dessem exemplos, a resposta foi de que não possuíam conhecimento ou evidências de que esse fato teria acontecido. Portanto ficou claro com todos os atores que o método apesar de ter 0 seu conhecimento disseminado, mas na prática não tenha ocorrido.

Referente item: Capacitação

Ficou evidente pelas observações efetuadas pela pesquisadora no decorrer desses quinze anos em visitas sistemáticas e pelo resultado das entrevistas realizadas que principalmente nas secretarias instrumentais para a implantação do Programa de Modernização, de uma forma geral o mais importante com a introdução desse modelo de gestão foi a introdução de novas metodologias de gestão no Governo, que estão em uso até hoje, e a formação de quadros profissionais para a Administração Pública.

Referente item: Sistema de Informação

Este estudo pelo resultado das entrevistas não conseguiu identificar se o sistema de informação da forma como havia sido proposto para adaptá-lo ao modelo de gestão de forma a vir a avaliar o desempenho da gestão, não conseguiu progredir nesse sentido. Pois o sistema deveria ter os itens de verificação e de controle.

Ao que parece, o sistema de informação não conseguiu ser implantado para contribuir com as mudanças da forma e com a velocidade que o processo exige verificar o giro do ciclo PDCA.

Referente item: Equipamentos, Tecnologia

Foi citado pelos atores entrevistados a modernização da estrutura de atendimento da Sefaz, com destaque para as agências fazendárias e toda a implantação de tecnologia da informação na área tributária. Mas ainda existem deficiências de hardware, software e pessoal em alguns pontos e que precisam ser sanados. Cita-se ainda introdução da INFOVIA e do SIGPEX.

Referente item: Sistema de Informação Contábil

A contabilidade tem pelos entrevistados, um papel fundamental dentro do sistema de informação pois através dela todos os atos e fatos são registrados sendo fundamental o seu papel não só em relação aos aspectos legal de registro das transações financeiras e patrimoniais executadas pelo Poder Executivo. Citam os atores entrevistados que ela pode também se tornar um importante instrumento gerencial nesse processo com a adoção de metodologias inovadoras como ABC (sistema de custeamento), rateio de despesas por centro de custo, dentre outras.

A função seria de controladoria, contabilidade que demonstrasse também os resultados alcançados para o cidadão, o que não aconteceu foi o que um dos atores entrevistados respondeu.

Fonte: Dados da pesquisa, elaborada pelos autores.

O Quadro 4 sintetiza as características de inovação identificadas no projeto de Modernização da Administração Financeira do Governo de Mato Grosso - GPD (Gestão pelas Diretrizes), conforme recomendado pelo Manual de Oslo (2005).

Quadro 4 - Síntese das características de inovação apontadas neste estudo

\section{\begin{tabular}{|l|l} 
Dados Descritivos (Manual de & Realização (Governo MT) \\
\hline
\end{tabular}}




\begin{tabular}{|c|c|}
\hline Oslo) & \\
\hline Descrição da inovação principal & $\begin{array}{l}\text { Implementação da Gestão pelas Diretrizes } \\
\text { com o uso da técnica PDCA }\end{array}$ \\
\hline Tipo de inovação & Inovacão em processos administrativos \\
\hline Classificação da Inovação & Incremental \\
\hline $\begin{array}{l}\text { Classificação da novidade } \\
\text { técnica }\end{array}$ & $\begin{array}{l}\text { Introdução de novas tecnologias de } \\
\text { trabalho: inserção de tecnologia da } \\
\text { informação na área tributária, Infovia, Plano } \\
\text { de Trabalho Anual (PTA) como elo entre } \\
\text { plano e orçamento. }\end{array}$ \\
\hline $\begin{array}{l}\text { Classificação da novidade em } \\
\text { termos de mercado }\end{array}$ & Novo apenas na organização \\
\hline Natureza da inovação & Melhoria e mudança técnica \\
\hline $\begin{array}{l}\text { Dados quantitativos - Gastos } \\
\text { com a inovação }\end{array}$ & $\begin{array}{l}\text { Foi feito financiamento pelo PNAFE } \\
\text { utilizando recurso do BID, mas não foi } \\
\text { possível precisar com detalhes a quantia e } \\
\text { como foi usado. }\end{array}$ \\
\hline Impacto da Inovação & $\begin{array}{l}\text { Os funcionários passaram a trabalhar com } \\
\text { clareza dos objetivos e metas para aferir os } \\
\text { resultados periodicamente. } \\
\text { Extensão do projeto, além da SEFAZ, para } \\
\text { outras secretarias (SAD, SEPLAN, AGE e } \\
\text { Cepromat). }\end{array}$ \\
\hline Ciclo de vida da inovação & $\begin{array}{l}\text { O período utilizado do planejamento à } \\
\text { execução foi de } 1998 \text { a } 2001 \text {, muitas ações } \\
\text { permanecem outras continuam sendo } \\
\text { melhoradas. }\end{array}$ \\
\hline $\begin{array}{l}\text { Dados Qualitativos - Benefícios } \\
\text { da Inovação }\end{array}$ & $\begin{array}{l}\text { Quinze anos após a implantação da } \\
\text { Gestão pelas Diretrizes é possível aferir } \\
\text { nas palavras dos atores entrevistados, } \\
\text { indicadores qualitativos advindos da } \\
\text { inovação, quais sejam: estrutura de } \\
\text { atendimento da Sefaz, Plano de Carreira } \\
\text { de Gestores Governamentais, utilização de } \\
\text { metas, procedimentos administrativos, } \\
\text { transparência da aplicação dos recursos } \\
\text { públicos. }\end{array}$ \\
\hline
\end{tabular}

Fonte: Dados da pesquisa, elaborada pelos autores.

Os resultados obtidos demonstram que a Gestão pelas Diretrizes implantada nas Secretarias Instrumentais e de Fazenda do Mato Grosso se encaixam nas características inovadoras, conforme parâmetros de análise estipulados no Manual de Oslo. Os agentes envolvidos também percebem os pontos positivos dessa gestão, tanto que a maioria dos entrevistados reconhecem os benefícios que ainda permaneceram desde o início do projeto.

Vale ressaltar a importância da capacitação de servidores como ponto positivo para disseminar o conhecimento e de introduzir novas metodologias de gestão principalmente na Secretaria de Fazenda de Mato Grosso. 


\section{CONSIDERAÇÕES FINAIS}

Pouco mais de uma década após a adesão ao Projeto de Modernização este estudo pode mostrar que a utilização do método PDCA se mostrou eficaz na aplicação da gestão pública da Secretaria de Aplicação - SEFAZ do Governo do Mato Grosso na implantação do Projeto de Modernização da Administração Pública do Governo do Estado de Mato Grosso.

Também foi possível identificar na implantação deste modelo de gestão características que podem se relacionar aos conceitos de inovação descritos por Schumpeter (1982) e ao conceito de inovação no setor público conforme estudado por Mulgan and Albury (2003), pois a tratou-se de novidade na solução de problemas existentes e inclusão de novos serviços e de melhoria de novos processos.

Verifica-se, pelos resultados obtidos por meio das entrevistas, que o modelo de gestão implantado que privilegia a avaliação de desempenho da gestão pública com a utilização do método PDCA e modelo Gerenciamento pelas Diretrizes trouxe resultados significantes para algumas Secretarias de Estado, principalmente as consideradas instrumentais para implantação do programa (Secretaria de Fazenda, Secretaria de Administração, Secretaria de Planejamento e Auditoria Geral do Estado).

Mesmo nas Secretarias Instrumentais, nem todas alcançaram o mesmo grau de inovação nos processos, isso pode ser observado pelo resultado das entrevistas, portanto faltou um quesito importante que é a disseminação do conhecimento às demais Secretarias de Estado.

Um dos pressupostos do modelo de gestão é ter foco para os resultados, para as atividades fins e não nos meios, ter o usuário como agente no processo e o orçamento do Estado e todo o planejamento concebido para gerar resultado, cada ação de desdobramento dos programas governamentais tinham metas e indicadores que pudessem ser medidos.

Pode-se verificar pelos resultados que o Manual do Gerenciamento pelas Diretrizes com relação às reuniões para avaliação das metas a nível operacional, ainda continua, isso significa que este conhecimento disseminado foi perfeitamente absorvido, devendo ser aperfeiçoado para prática do ciclo de ações corretivas e dessa forma melhorar o desempenho das ações gerencias.

Observa-se também que o comprometimento da alta administração com a modernização da administração pública é fator crítico de sucesso na gestão e tem como consequência as diferenças no grau de implantação entre as Secretarias Instrumentais, destaca-se entre elas a SEFAZ.

Outro fator que demonstra o comprometimento com o projeto implantado pode ser aferido no site da SEPLAN que esta voltou a elaborar o Plano Plurianual (PPA) 2012/2015 com metas, objetivos, valor e prazo, possibilitando, assim, a possibilidade para se avaliar os resultados das ações planejadas. 


\section{REFERÊNCIAS}

BARBOSA, Ines N.; GILIOLI, Esther I. S. Proposta de Programação Financeira para o Sistema Integrado de Administração Financeira Estadual-SIAF/MT: Secretaria de Estado de Fazenda, 1992.

BOGDAN, Robert; BIKLEN, Sari. Investigação qualitativa em educação: uma introdução à teoria e aos métodos. Porto (Portugal): Porto, 1994.

CARVALHO, Maria do Socorro M. V.; TONET, Helena. C. Qualidade na administração pública. [Artigo). RAP, Rio de Janeiro 28(2): 137-S2. ABR./IUN. 1994.

DOSI, Giovanni. The nature of innovative process. In Dosi, G. et al. Technological change and economic theory. Londres: Pinter Publishers, 1988.

FALCONI, Vicente. Gerenciamento da Rotina - do trabalho do dia-a-dia. $5^{\mathbf{a}}$ ed. Belo Horizonte: Fundação Christiano Ottoni. 1996a.

FALCONI, Vicente. Gerenciamento pelas Diretrizes (Hoshin Kanri). $2^{a}$ ed. MG: Fundação Christiano Otoni, 1996b.

FERREIRA, Aurélio. B. de $\mathrm{H}$. Mini Aurélio: o dicionário da língua portuguesa. $8^{\mathrm{a}}$ ed. Curitiba: Positivo, 2010.

GIL, Antonio C. Como elaborar projetos de pesquisa. $3^{\text {a }}$ ed. São Paulo: Atlas, 1996.

GIL, Antonio C. Métodos e técnicas de pesquisa social. $5^{\mathrm{a}}$ ed. São Paulo: Atlas, 1999.

GOMES, Ricardo. C. Análise exploratória da perspectiva de implantação da filosofia da qualidade na administração pública. [Artigo]. RAP: Rio de Janeiro 31(3):48-58, 1997.

LUCIARDO, Renildes $O$. Uma contribuição para obtenção de qualidade na gestão de despesas públicas com o uso da avaliação de desempenho vinculada à proposta orçamentária. (Dissertação de Mestrado), Professor Orientador: Dr. Nelson Petri. PUC - Pontifícia Universidade Católica de São Paulo, 2000.

MANUAL DE OSLO. $3^{\text {a }}$ ed. 2005. Disponível em: http://www.mct.gov.br. Acesso em 20/04/2013.

MATTHEWS, Mark; LEWIS, Chris. e COOK, Grahame. Public Sector Innovation: A Review of the Literature, 2009. Disponível em: http://www.anao.gov.au/uploads/documents/Suppliment_Literature

Review.pdf. Acesso em 31/05/2013.

PPA - Plano Plurianual de Governo de Estado/MT - 2000-2003. Mato Grosso, 1999.

MAXIMIANO, Antonio C. A. Teoria Geral da Administração. São Paulo: Atlas, 2004.

MORGAN, Goreth. Imagens da Organização. São Paulo: Atlas, 1996. 
MULGAM, Geoff; ALBURY, David. Innovation in the public sector. London: Gabinet Office Stragegy Unit. 2003.

QUEIROZ, Roberta G. M; CKAGNAZAROFF, Ivan B. Inovação no setor público: uma análise do choque de gestão (2003-10) sob a ótica dos servidores e dos preceitos teóricos relacionados à inovação no setor público. [Artigo]. RAP: Rio de Janeiro 44(3):679-705, Maio/jun. 2010.

SCHUMPETER, Joseph. A. Teoria do Desenvolvimento Econômico: uma investigação sobre lucros, capital, crédito, juro e o ciclo econômico. São Paulo: Abril Cultural, 1982.

SHEFFER, Esther. I. Modelo de Gestão para uma Administração Pública Gerencial. (Monografia) UNIC - Universidade de Cuiabá, 2000.

SILVA, Reinaldo O. Teorias da Administração. São Paulo: Pioneira Thomson Learning, 2005.

TEIXEIRA, Hélio J.; SALOMÃO, S, M. e TEIXEIRA, C. J. Fundamentos de Administração: a busca do essencial. Rio de Janeiro: Elsevier, 2010.

TEIXEIRA, Hélio J.; SANTANA, S. M. (Coord) et alii. Remodelando a Gestão Pública - Uma revisão dos princípios e sistemas de planejamento, controle e avaliação de desempenho. São Paulo: Editora Edgard Blücher Ltda, 1994.

TIDD, Joe; BESSANT, Jonh; PAVITT, Keith. Gestão da Inovação. Tradução: Elizamari Rodrigues Becker...[et.al). 3 ${ }^{\underline{a}}$ Ed. Porto Alegre: Bookman, 2008.

TRIVIÑOS, Augusto N. S. Introdução à pesquisa em ciências sociais: a pesquisa qualitativa em educação. São Paulo: Atlas, 1987. 